\title{
A NONINTERMITTENT SENSITOMETER (TIME-SCALE EXPOSURE MACHINE) WITH CLOCK-CONTROLLED MOTOR DRIVE
}

\author{
By Raymond Davis
}

\section{ABSTRACT}

The work of the Bureau of Standards, in studying photographic materials and processes, has a threefold objective, namely, an inquiry regarding the nature and causes of photographic action and phenomena, the application of photography to scientific research, and the standardization of the methods and procedure for testing photographic materials. The sensitometer described in this paper is a special instrument designed for both research and testing purposes, and has, therefore, a more extended exposure range than is necessary for testing purposes. It is a sector-wheel machine in which the entire exposure takes place during one revolution. The sector wheel may be run at a wide range of speeds of from 480 to $0.0586 \mathrm{r}$. p. $\mathrm{m}$. This speed range is covered in steps varying by powers of two, and is obtained by means of ehange gears that connect the sectorwheel shaft with either of two other shafts which are driven through worms and gears by a constant speed motor at fixed, but different speeds. A new arrangement of the apertures in the sector wheel is used. The principal details of the construction and calibration of the sector wheels are given.

To drive the sensitometer a special circuit has been devised in which the shuntwound motor is adapted to the centrifugal governor for maintaining constant speed. An additional refinement has been added whereby clock signals are applied to automatically and promptly compensate for small speed irregularities.

\section{CONTENTS}

I. Introduction

II. Design _......... 347

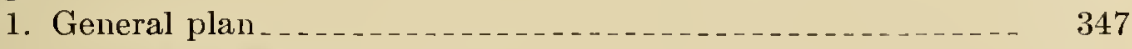

2. Driving the sector wheel

3. A high-speed precaution $\ldots \ldots$. 351

4. Elimination of backlash _... 351

III. Sector wheels _.

1. Sector-wheel design _........... 351

2. Balancing the sector wheels

3. Notes on sector-wheel construction

4. Calibration of the apertures._._. 355

IV. Plate holder, lamp, and shutter details 358

1. Plate holder

2. Standard lamps $\ldots \ldots \ldots \ldots$

3. Shutter

4. Shutter signal _............... 362

V. Speed regulation

1. Constant-speed driving motor

2. Comparison of machine speed with clock_....... 366

3. An automatic synchronizer. 367

VI. Summary _........... 370

VII. Bibliography 


\section{INTRODUCTION}

In our sensitometric work on plotographic materials the need has been felt for a sensitometer (exposure machine) of more flexible design than the intermittent apparatus described in Scientific Paper No. 439 (1). ${ }^{1}$ With that instrument the rate of speed of the sector wheel is one revolution per second, the light intensity one candle meter at the test plate, color temperature $5,325^{\circ}$ absolute, and the exposure required for fast and medium speed plates is 16 revolutions. Under these conditions the errors caused by the intermittent (2) exposures are small

Althougn this sensitometer has proven entirely satisfactory for general testing, it is not so desirable for studies of certain problems in sensitometry as a nonintermittent apparatus would be; for example, in the study of the failure of the reciprocity law of exposure time and light intensity, (3) because the large number of interruptions with small intensities of light, would, without question, cause serious errors.

The design of a sensitometer must depend considerably upon the special nature of the work for which it is to be used. Of previous designs two by Jones (4) of nonintermittent sensitometers are noteworthy. The exposures in the first are controlled by a solenoid which moves a shutter plate in steps in front of the photographic material. The time intervals of the steps are determined by the spacing of perforations in a strip of motion-picture film driven at a constant rate, through which an electrical contact lever operates. The timing of this machine may be changed by substituting another strip of film having perforations spaced to suit the requirements. This sensitometer is adapted for use with small light intensities only as the shutter can not be moved with sufficient precision for exposures less than one-fourth of a second. The other machine by Jones (5) is of the sector-wheel type in which the exposures take place during one revolution only. The speed of the sector wheel is variable through the enormous range of from 1,280 to $0.000614 \mathrm{r}$. p. m. All of this range is not available, however, as the light-operating mechanism was found not to function satisfactorily at the higher velocities. Apparently the maximum operating speed is $320 \mathrm{r}$. p. m. The sector wheel is 30 inches in diameter, has 10 steps in the usual powerof-two ratio, and the largest aperture is $240^{\circ}$. This instrument was designed primarily for a study of the reciprocity law.

Jones (6) and Higson (7) describe two machines in which an aperture plate is moved in a linear motion; the first one mentioned has step apertures, the other is a continuous wedge-shaped aperture.

1 The figures given in parentheses here and throughout the text relate to the reference numbers in bibliography at the end of this paper. 
A linear aperture plate has the advantage of ease in calibration, but is more difficult to move at a uniform rate than a balanced sector wheel.

Quite recently in the design of another nonintermittent sensitometer by Hardy (8) a method is given for extending the scale of the sector wheels to 15 power-of-two steps, or even more, by using 2 wheels rotating at different velocities about a common center, on sleeve shafts, connected by gearing. The large wheel has the usual 9 steps, while the other 6 steps are on a smaller wheel having a radius equal to that of the aperture section of the large wheel. The exposures given by the small wheel take place through an auxiliary aperture in the large wheel. The relative speed of rotation is such that the exposure time of the largest aperture of the small wheel is one-half the smallest aperture of the larger wheel. The smallest aperture of the large wheel is $0.703^{\circ}$, the large aperture of the small wheel is $22.5^{\circ}$, hence the small wheel must revolve at 64 times the rate of the large one. As actually constructed, the machine has a total of 13 steps. It is driven at a fixed speed by an alternatingcurrent motor running at speed of $1,800 \mathrm{r}$. p. m. plus or minus 1 per cent, which is sufficient accuracy for testing purposes. It is not flexible enough, however, for use on special problems.

Renwick (9) and others have driven sector wheels for one revolution only during the exposure period by spring and electric motors, but complete descriptions of these have not been found.

\section{DESIGN}

\section{GENERAL PLAN}

The exposure apparatus is a sector-wheel machine in which the sector wheel is rotated over a wide range of speeds, the exposure taking place during one revolution only. The range of speeds is from 480 r. p. m. down to 0.0586 r. p. m. in power-of-two ratio steps, which is somewhat more than sufficient to cover the range of sensitive material to be tested and allow a good margin on each side for experimental purposes. Thus, the design is such that the apparatus is equally well adapted for usual testing and for special work on reciprocity.

As shown in Figure 1 the sector wheel is housed in the light-tight metal case, $A$, adjoining which is a gear case, $B$, and the light tunnel, $C$. This tunnel is adjustable in length by a bellows section, and also by removable rigid sections. Reflections from the side walls are prevented by a number of carefully placed diaphragms. The end section carries the shutter, lamp house, and light filters. At $D$ are shown two slides, one for holding the blue-glass compensating filter and the other for such other light filters as may be desired. 


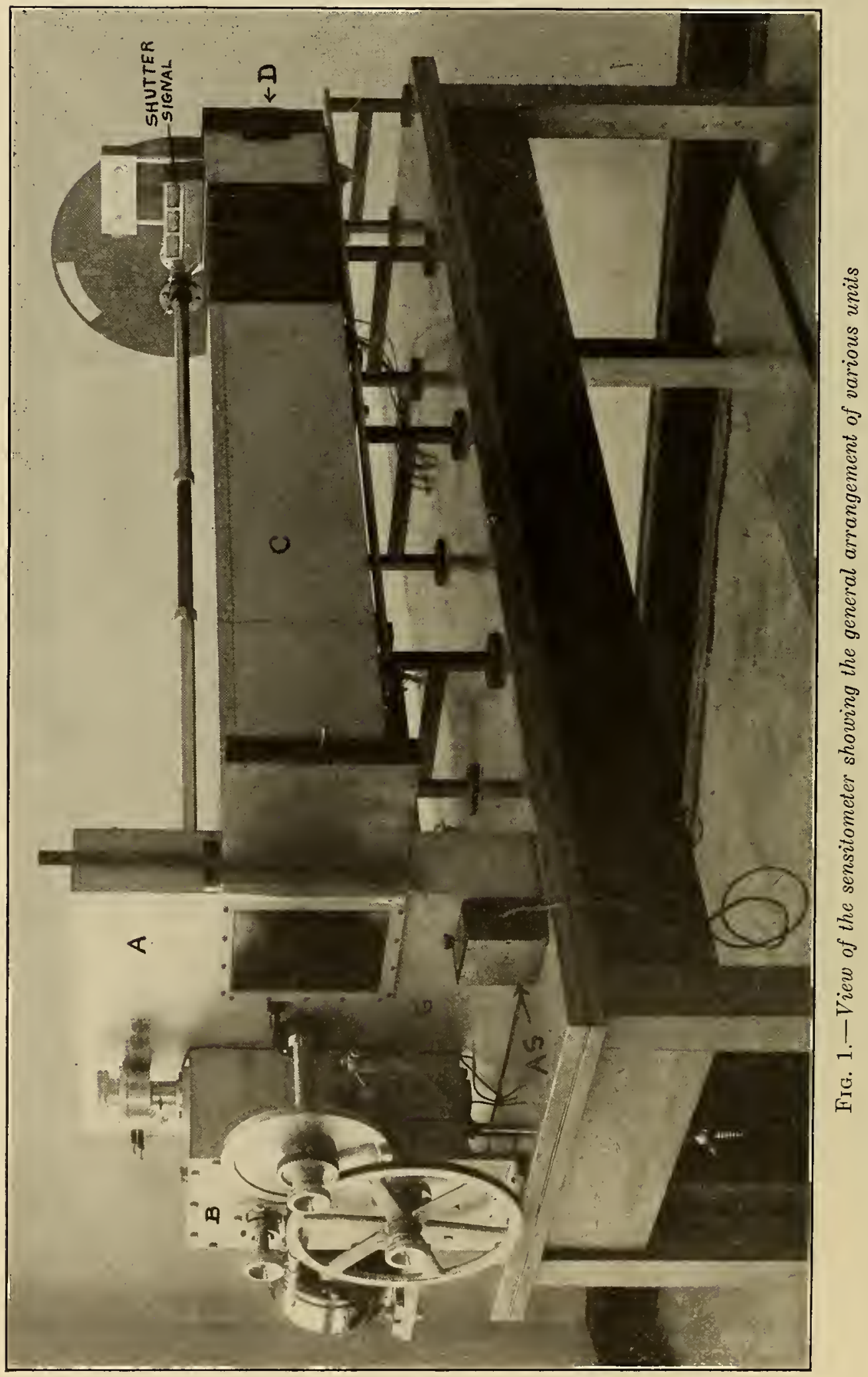




\section{DRIVING THE SECTOR WHEEL}

A motor running at a constant speed drives through a system of worm gears two shafts, either of which may be connected to a third, the sector-wheel shaft, by change gears. Figure 2, from a photograph made during the construction, shows the worm gear train. The motor, $M$, which runs at 1,500 r. p. m., drives the lower gear, $L G$, through the worm, IF1. This worm has a double thread and the

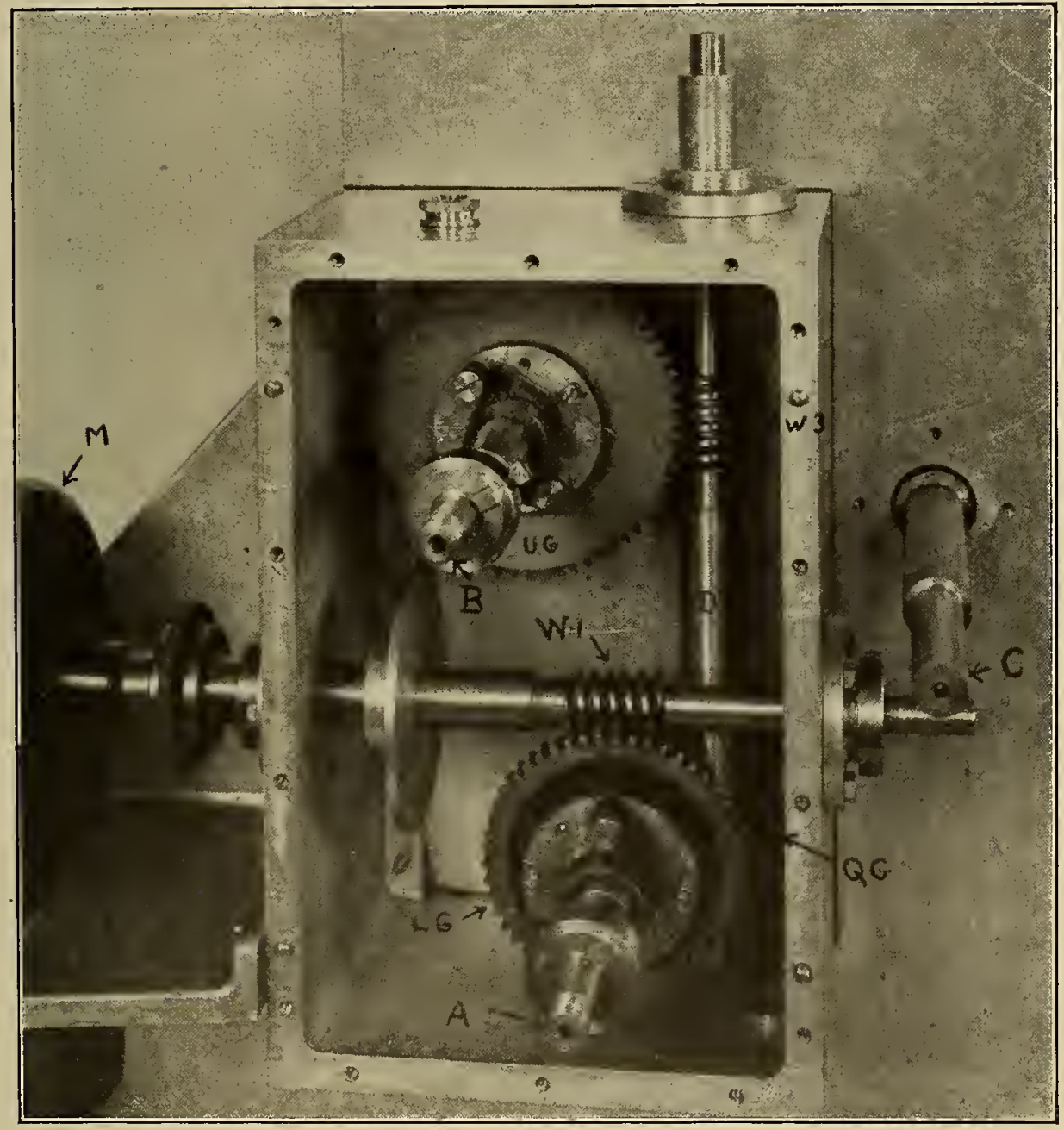

FrG. 2.-Interior view of the gear case showing the gear train

gear has 50 teeth so that the shaft, $A$, is driven at 60 r. p. m. Back of the gear, $L G$, on the shaft, $A$, is a quadruple thread worm which drives a 16-tooth gear, $Q G$, just visible on the shaft, $D$. This shaft revolves at the rate of $15 \mathrm{r}$. p. m., and in turn drives the shaft, $B$, through the worm, W3, and the gear, UG. This worm is also double thread. The gear, $C G$, has 64 teeth so that the shaft, $B$, revolves at $1 / 128$ the speed of shaft, $A$, or 0.46875 r. p. m. Care was exercised to obtain gears of high quality and workmanship. All of the parts 
are fitted with ball bearings to minimize friction. The lower gears run in oil and the upper gears are oiled by a splash method.

Shafts $A$ and $B$ are so placed with regard to shaft $C$ (the sectorwheel shaft) that the distance (between shaft centers) from $A$ to $C$ and from $B$ to $C$ is exactly the same.

These distances correspond to the centers of four pairs of helicalchange gears having, respectively, the ratios 1 to 1,2 to 1,4 to 1 , and 8 to 1 . The following table gives the principal dimensions.

$\mathrm{T}_{\mathrm{ABLF}}$ 1.-Dimensions of change gears ${ }^{1}$

\begin{tabular}{|c|c|c|c|c|}
\hline Gear ratio & $\begin{array}{c}\text { Number } \\
\text { of teeth } \\
\text { hobbed } \\
\text { R. A. }\end{array}$ & $\begin{array}{c}\text { Pitch } \\
\text { diameter }\end{array}$ & $\begin{array}{l}\text { Number } \\
\text { of teeth } \\
\text { hobbed } \\
\text { L. H. }\end{array}$ & $\begin{array}{c}\text { Pitch } \\
\text { diameter }\end{array}$ \\
\hline $\begin{array}{l}1 \text { to } 1 \\
2 \text { to } 1 \\
4 \text { to } 1 \\
8 \text { to } 1\end{array}$ & $\begin{array}{r}135 \\
90 \\
54 \\
30\end{array}$ & $\begin{array}{l}\text { Inches } \\
7.183 \\
4.789 \\
2.873 \\
1.596\end{array}$ & $\begin{array}{l}135 \\
180 \\
216 \\
240\end{array}$ & $\begin{array}{r}\text { Inches } \\
7.183 \\
9.577 \\
11.493 \\
12.770\end{array}$ \\
\hline
\end{tabular}

$120^{\circ}$ Helical gears, 20 normal piteh, one-half inch face.

Helical gears were selected in preference to plain gears, because by their use it is possible to obtain a smoother and more even motion.

The gear and sector wheel cases are from castings of a copper aluminum alloy given a sand-blasted finish.

The following table gives the available speeds of the sector wheel shaft:

TABLE 2.-Sector wheel speeds

CHANGE GEARS ON SHAFTS A AND $C$

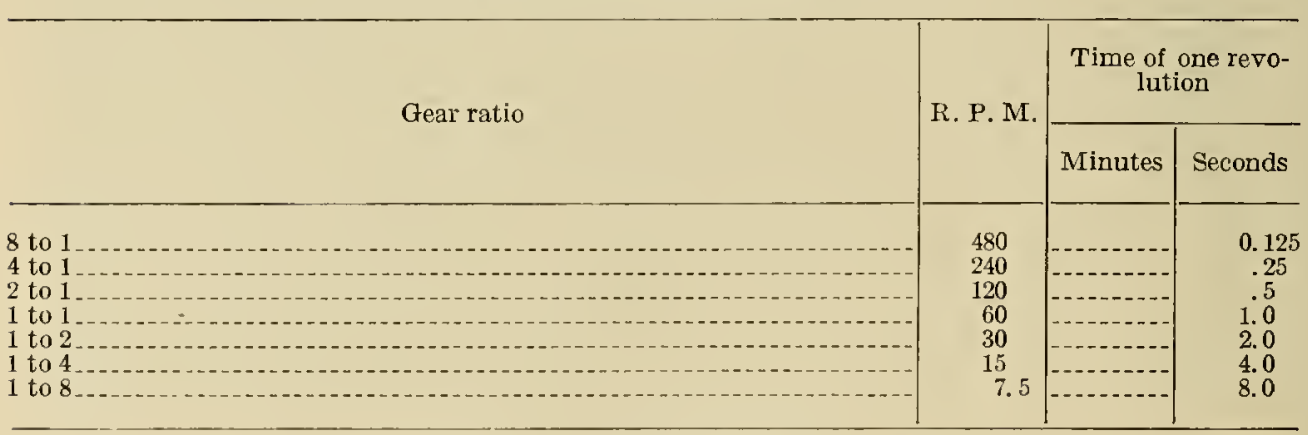

CHANGE GEIRS ON SIIAFTS $B$ AND $C$

\begin{tabular}{|c|c|c|c|}
\hline 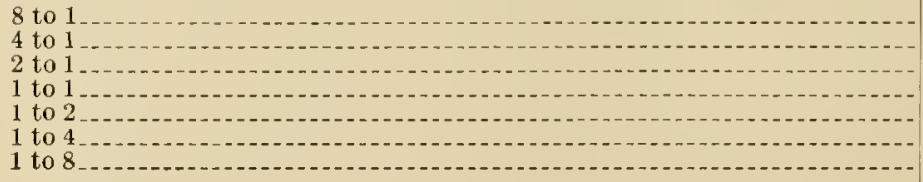 & $\begin{array}{l}3.75 \\
1.875 \\
.9375 \\
.4687 \\
.2344 \\
.1172 \\
.0586\end{array}$ & $\begin{array}{r}1 \\
2 \\
4 \\
8 \\
17\end{array}$ & $\begin{array}{r}16 \\
32 \\
4 \\
8 \\
16 \\
32 \\
4\end{array}$ \\
\hline
\end{tabular}




\section{A HIGH-SPEED PRECAUTION}

Inasmuch as the sector wheels used in this machine weigh approximately $3.6 \mathrm{~kg}$ (8 pounds), serious damage might occur to the driving mechanism at the higher speeds if the motor were suddenly stopped unless some provision be made to release the heavy wheel. This has been accomplished in the following manner: The gears, $L G$ and $U G$ (fig. 2), are free to revolve on their shafts, $A$ and $B$, in one direction, each driving its shaft through two pawls, secured to the gear, which engages with a ratchet fastened to the shaft. When the motor is stopped, the sector wheel may continue to rotate, driving through the change gears the shaft, $A$ or $B$, without strain on the mechanism.

\section{ELIMINATION OF GEAR BACKLASH}

In any train of gearing there is always present a certain amount of play between the driving and driven shafts, caused by necessary clearance between the faces of the teeth of the meshing gears and worms. Its effect must be eliminated, else the driven shaft will run at an uneven rate. Such a condition is revealed by the gear noise. Whenever the "clanking" is heard, uneven motion is present. A very simple and effective remedy for this is a brake, so placed that it provides a constant load on the entire gear system.

This brake wheel, shown in Figure 3 (approximately $20 \mathrm{~cm}(8$ inches) in diameter, and $13 \mathrm{~mm}$ (one-half inch) across the face), is mounted on the sector-wheel shaft. A leather-shod brake shoe is held against the face of the brake wheel, the pressure being varied to suit conditions by means of a long coil spring in a telescoping tube.

\section{SECTOR WHEELS}

\section{SECTOR-WHEEL DESIGN}

Sector wheels for giving graduated or step exposures to photographic materials have been in use ever since their adoption by Hurter and Driffield (10). Their design (fig. 4) since used by many others, had nine apertures, each having twice the angle of the preceding. Another common design is that by Scheiner (11) which has a large number of apertures, usually from 19 to 23 varying in the ratio of 1 to 1.27 .

In both of these types the smaller apertures are near the edge of the disk and the large ones near the center. Single apertures larger than $90^{\circ}$ are avoided because of weakening of the wheel, so this form could not be used in a nonintermittent sensitometer, as the last aperture would divide its exposure into two parts. This difficulty is surmounted by Jones (5) and Hardy (8), who reversed the order of the apertures, cutting the largest ones at the rim, though this arrangement, particularly with ordinary-sized wheels, has the disadvantage $46959^{\circ}-25-2$ 
of reducing the linear width of the smaller apertures, making them very difficult to cut out with the desired precision. For example, in a nine-step wheel of usual design with apertures in the power-of-two ratio the largest angle is $180^{\circ}$ and the smallest $0.703^{\circ}$. If the center

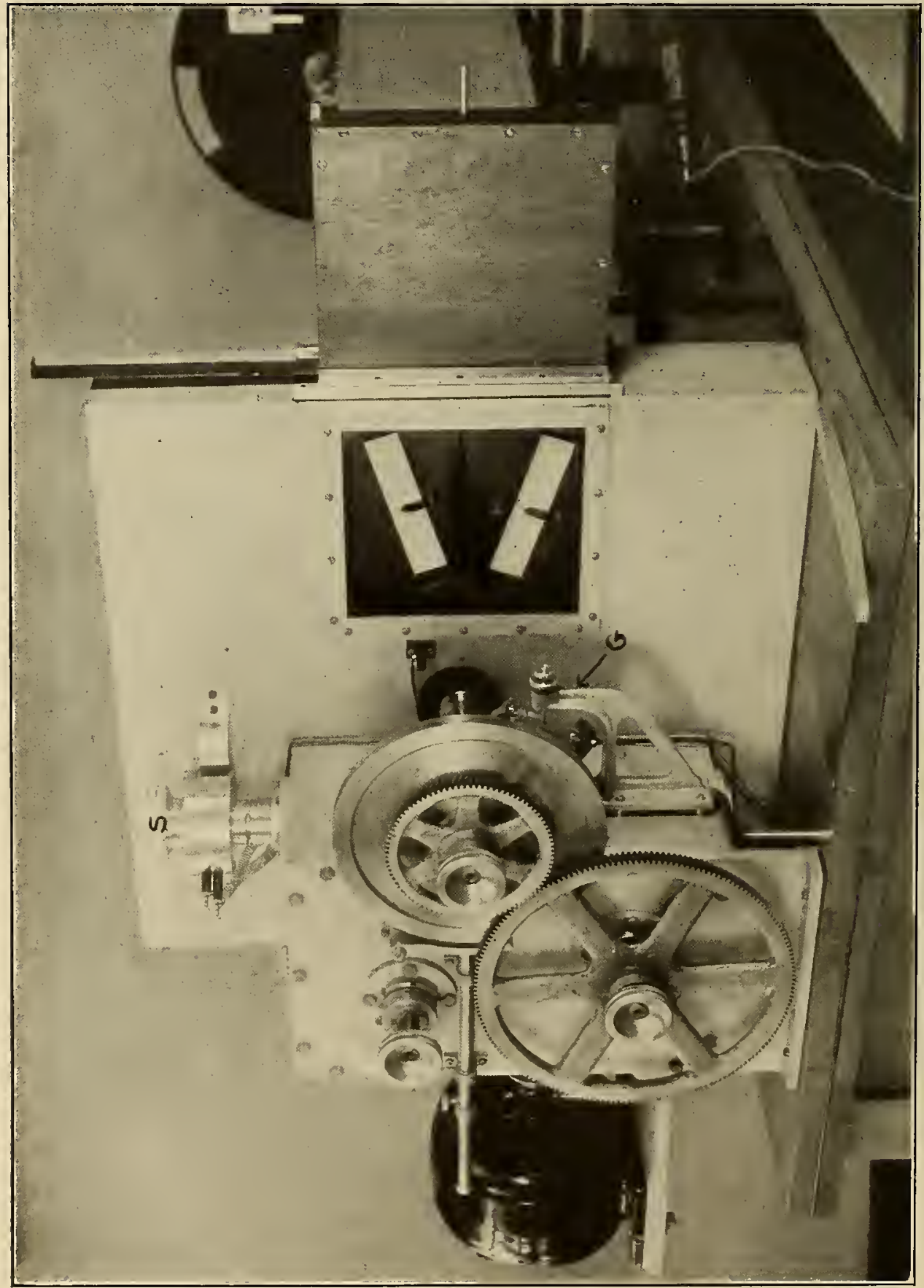

of the first aperture is $41 / 2$ inches from the wheel center and the radial length of each step is one-half inch, the center of the last or outside aperture will be 9 inches from the wheel center. With the small aperture outside, the distance across the center will be 0.1105 inch. 
Now if we reverse this order and place the small aperture inside $\left(41 / 2^{-}\right.$ inch radial length of center), the distance will be 0.0552 inch, or one-half the width obtained before. In this case it would be necessary to cut this aperture with a precision of 0.00055 inch in order to keep within an accuracy of 1 per cent.

By centering all apertures on the same radial line as shown in Figure 5 we have made a sector wheel of modified $H$ and $D$ form which gives

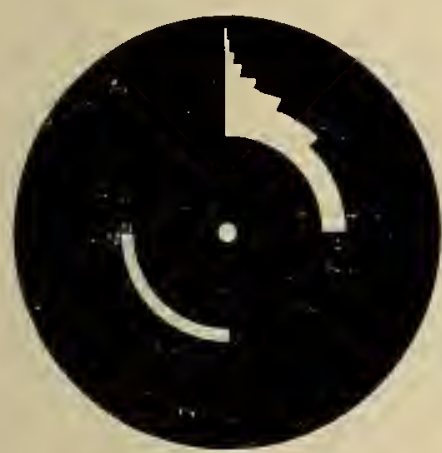

FIG. 4.-Sector wheel of $H$ and $D$ design

a single $180^{\circ}$ aperture without undue weakening. This wheel, with 13 apertures of two-thirds power-of-two (cube root of four) steps, and the others to be described were all made of one-eighth inch annealed sheet brass and are 19 inches in diameter. The aperture edges are all beveled on one side of the wheel except for a narrow edge of approximately one thirty-second inch, from which the angular measurements are made. The 13-step wheel has the same exposure scale (1 to 256) obtained with nine power-of-two steps, with the obvious advantage of giving a greater number of points from which to construct the characteristic curves. The radial length of the aperture section is $4 \frac{3}{4}$ inches.

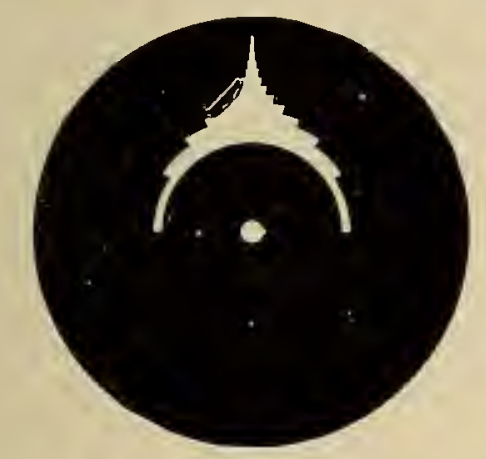

FIG. 5.-Sector wheel with symetrically placed apertures for nonintermittent sensitometer

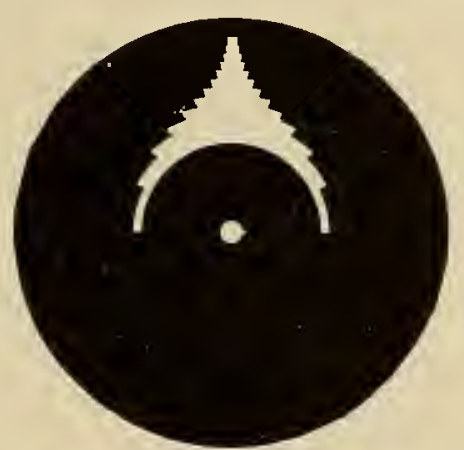

FIG. 6.-Wheel of similar design, but with smaller aperture ratio

A second wheel of similar design, shown in Figure 6, was constructed for use in sensitometry of emulsions on paper. This has 13 steps in the ratio of the square root of two and an exposure scale of 1 to 64 .

Two other special wheels are shown in Figures 7 and 8 . The singleaperture wheel, angular opening $2^{\circ} 48^{\prime} 45^{\prime \prime}$, is to be used for exposing one-half of a test plate to the higher intensities of light. The exposure times available with this wheel in the sensitometer are from $1 / 1024$ second to 8 seconds in power-of-two steps. 


\section{BALANCING THE SECTOR WHEELS}

In descriptions of sector wheel sensitometers mention is often lacking in regard to balancing the wheels to compensate for the mass of material removed from the apertures. An unbalanced wheel will, under usual circumstances, revolve at an uneven rate, hence the precision attained in the angular measurement of the apertures is wasted. Both static and dynamic balancing may be had with sufficient pre-

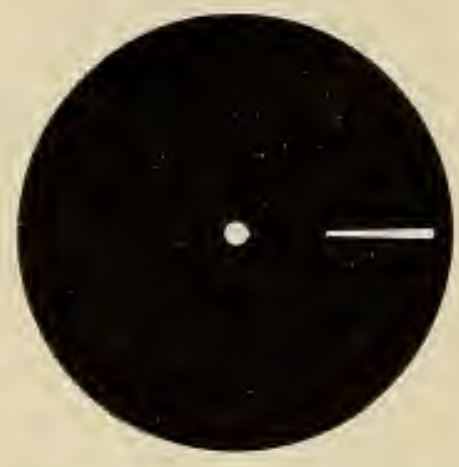

Fig. 7.-Single aperture sector wheel

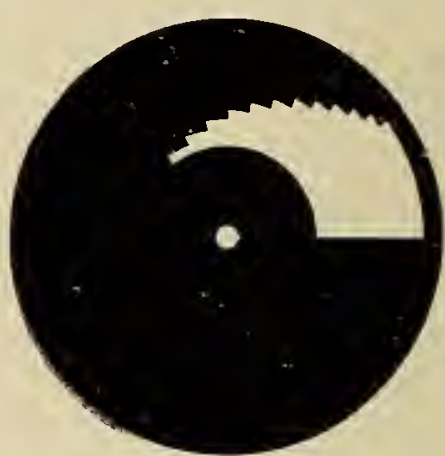

FIG. 8.-A special design of sector wheel

cision by fastening a thin counterpoise to the sector wheel, its mass and location being found mathematically.

Probably the best procedure is to use a weight the same thickness as the wheel, calculate its approximate size for a position at or near the rim, and find its actual location by static balancing. Another method which the writer has used is to cut a duplicate wheel out of
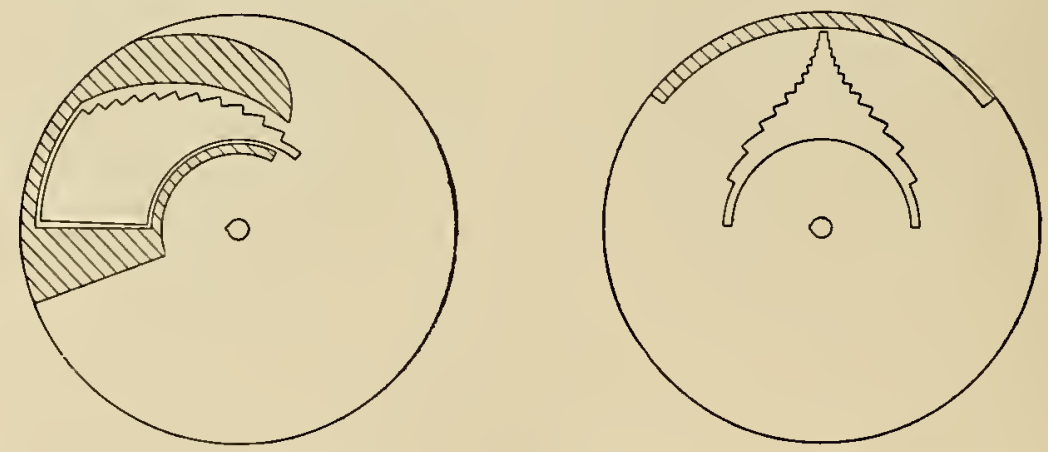

FIG. 9.--Showing the shapes and position of the balancing weights for two types of sector wheels

cardboard (cut the apertures with a wood chisel) and balance this on a point at the center of the wheel by trial, using pieces of the same cardboard as a counterpoise. This method has the advantage of simplicity and facility in determining a suitable shape for the counterpoise. The pieces finally decided on may then be used as a pattern from which the metal weight may be made. The correct location of the metal weight should, of course, be determined by trial in the same manner before it is permanently attached. 
It might be mentioned that the design shown in Figures 5 and 6 is more easily balanced than other types. In this the counterpoise is placed near the rim, and thus reinforces the small section outside of the apertures. Counterpoises as used for two types of wheels are shown in Figure 9.

\section{NOTES ON SECTOR-WHEEL CONSTRUCTION}

It may be of interest at this point to describe briefly the method followed in constructing the sector wheels. The metal disks were turned in a lathe from annealed sheet brass one-eighth inch thick, and then brought to the laboratory. A metal plug with a center indentation was fitted into the hole in the center of the disk. Using this hole as a center, concentric lines were then scribed to mark the radial limits of the apertures. The wheel was then mounted on a specially arranged spectrometer and the angles for the apertures scribed directly on the metal. The disk was then returned to the shop where the apertures were cut nearly to the angular limits,

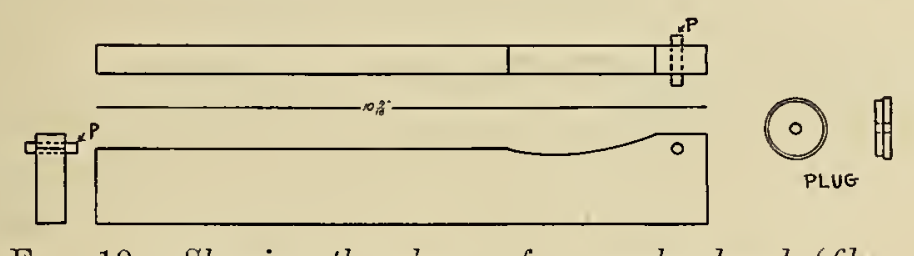

FIG. 10.-Showing the shape of a casehardened (fileproof) straightedge used in filing the apertures

and beveled. This procedure left all of the angles small. The wheel was again mounted on the spectrometer and measured, the filing of the apertures from this point on being done in the laboratory, measuring the angles whenever thought necessary to obtain high precision. It is important that the edges of the apertures be radial. This was obtained, together with control over the depth of filing, by using a casehardened steel straightedge (shown in fig. 10) which was clamped to the sector wheel. The plug fits the shaft hole in the wheel and the projecting pin, $P$, which is in accurate alignment with the straightedge, fits a small hole in this plug.

The finished wheels were first blackened with ammoniacal copper carbonate, and this followed with two coats of black shellac, the shellac being, of course, carefully removed from the edges of the apertures.

\section{CALIBRATION OF THE APERTURES}

It would appear from the literature that the apertures of sector wheels are not usually measured with a divided circle. The usual practice is to measure the linear width of the smaller angles and to assume the correctness of the larger ones after rough checking. $46959^{\circ}-25-3$ 
There are two apparent reasons for the adoption of this procedure, first, a divided circle is not generally available in a convenient form for measuring the aperture angles, and second, because of the tedious process necessary to obtain accurate results. A third possible reason is that it may be considered unnecessary to strive for precision in this when corresponding accuracy is not attained in sensitometric work because of inequalities in emulsions, irregularities in derelopment, density measurement, etc. This is reasonable, but, inasmuch

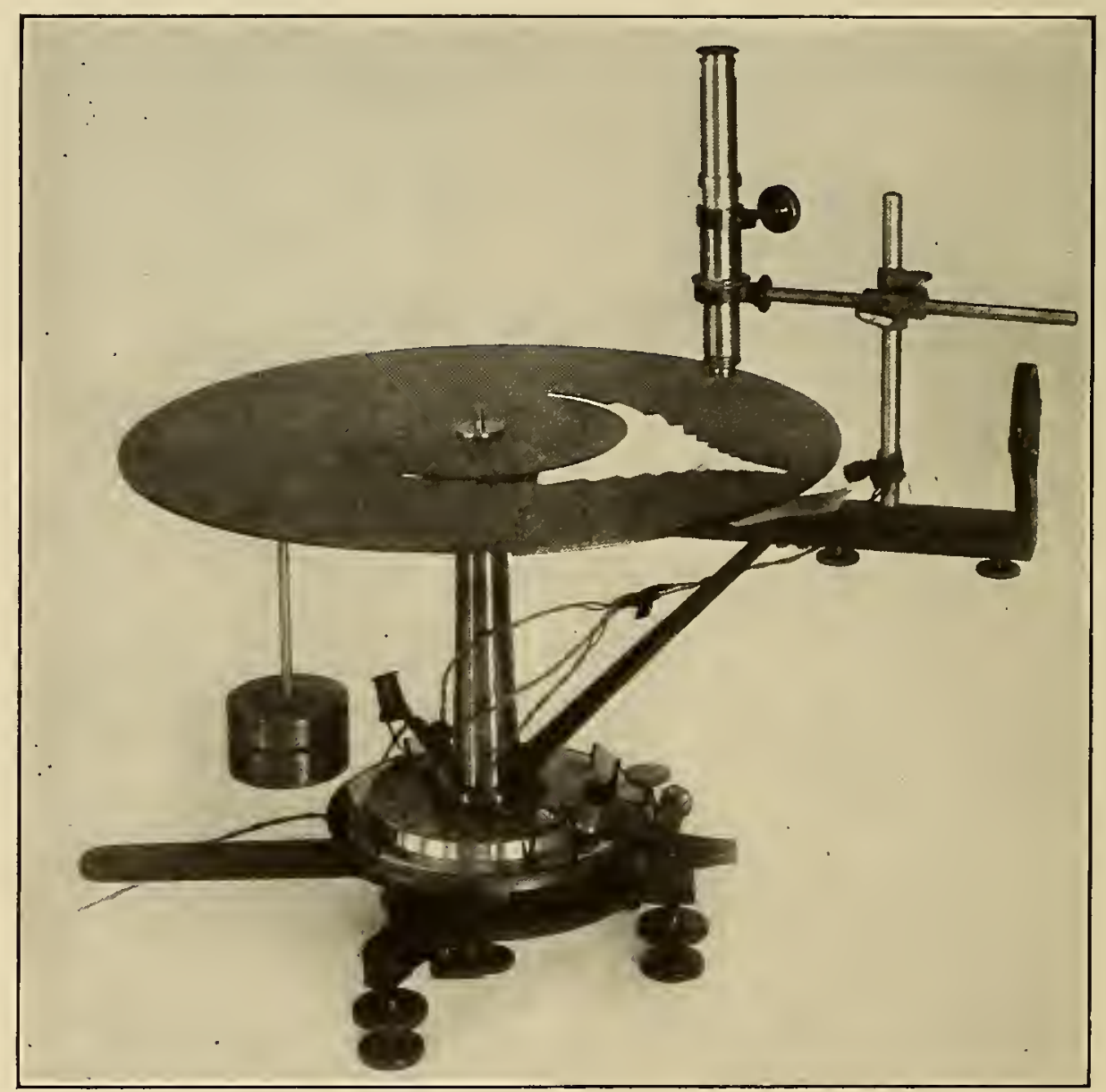

Fig. 11. - A view of the spectrometer with a seetor wheel mounted in position for the calibration of the aperture angles

as the errors in the sector wheel affect all the data obtained by its use, it is very desirable to know with reasonable certainty their magnitude. An accuracy of 1 per cent is sufficient for general sensitometric work, but for special problems, such as the reciprocity work where comparisons are made at adjacent places on the same plate, greater accuracy seems desirable.

In the calibration of these wheels an old type spectrometer was used. This instrument has an 8-inch circle, and four verniers which read to 10 seconds. $\Lambda$ brief study was made of the circle to determine 
the quality of the instrument. It was found that it had an eccentricity error (maximum) of 25 seconds. The errors in graduations, determined by vernier comparisons at a number of points around the circle did not exceed 10 seconds at any point.

For purposes of calibration the sector wheel is mounted on the spectrometer as shown in Figure 11. The wheel and the graduated circle are stationary, the arm carrying the microscope is movable, and the verniers move with it. One edge of the aperture is set on the fiduciary line in the microscope and the positions of the two verniers, $A$ and $C$, which are $180^{\circ}$ apart, are recorded. Another setting is made on the other edge of the aperture in the same manner. The mean of the differences between the two positions of each of the verniers is the angle of the aperture, which includes an error due to eccentricity of the wheel mounting. To eliminate this error similar measurements are made after rotating the sector wheel through an angle of $90^{\circ}$. This is repeated until it has been read in the four $90^{\circ}$ positions, the mean of these data being taken as the true angle. This procedure is repeated for each aperture.

The following tables give the results of such a calibration of two of the sector wheels:

TABLE 3.-Sector wheel, square root of two aperture ratio. Scale 1 to $64_{4}$

\begin{tabular}{|c|c|c|c|c|c|c|c|}
\hline \multicolumn{3}{|c|}{$\begin{array}{l}\text { Intended } \\
\text { angles }\end{array}$} & \multicolumn{3}{|c|}{$\begin{array}{l}\text { Measured } \\
\text { angles }\end{array}$} & \multicolumn{2}{|c|}{ Error } \\
\hline 。 & ' & " & 。 & ' & " & & \\
\hline 2 & 48 & 45 & 2 & 48 & 52 & & 7 \\
\hline & 58 & 40 & & 58 & 36 & & 4 \\
\hline 5 & 37 & 30 & 5 & 37 & 15 & & 15 \\
\hline 7 & 56 & 40 & 7 & 56 & 35 & & 5 \\
\hline 11 & 15 & 00 & 11 & 15 & 19 & & 19 \\
\hline 15 & 54 & 30 & 15 & 54 & 21 & & 9 \\
\hline 22 & 30 & 00 & 22 & 29 & 35 & & 25 \\
\hline 31 & 49 & 10 & 31 & 49 & 1 & & 9 \\
\hline 45 & 00 & 00 & 45 & 00 & 57 & & \\
\hline 63 & 32 & 35 & 63 & 32 & 36 & & \\
\hline 90 & 00 & 00 & 89 & 59 & 51 & & 9 \\
\hline 126 & 41 & 25 & 126 & 41 & 12 & & 13 \\
\hline 180 & 00 & 00 & 180 & 00 & 40 & & 40 \\
\hline
\end{tabular}

TABLE 4.-Sector wheel, two-thirds power-of-two ratio. Scale 1 to 256

\begin{tabular}{|rrr|rrr|rr|}
\hline 0 & $\prime$ & $\prime \prime$ & 0 & $\prime$ & $\prime \prime$ & , & $\prime \prime$ \\
0 & 42 & 10 & 0 & 42 & 5 & 0 & 5 \\
1 & 7 & 00 & 1 & 7 & 12 & 0 & 12 \\
1 & 46 & 20 & 1 & 46 & 11 & 0 & 9 \\
2 & 48 & 45 & 2 & 48 & 10 & 0 & 35 \\
4 & 27 & 50 & 4 & 27 & 24 & 0 & 26 \\
7 & 5 & 15 & 7 & 5 & 12 & 0 & 3 \\
11 & 15 & 00 & 11 & 15 & 6 & 0 & 6 \\
17 & 54 & 00 & 17 & 53 & 48 & 0 & 12 \\
28 & 20 & 50 & 28 & 20 & 52 & 0 & 2 \\
45 & 00 & 00 & 45 & 00 & 14 & 0 & 14 \\
71 & 26 & 00 & 71 & 26 & 55 & 0 & 55 \\
113 & 23 & 20 & 113 & 24 & 52 & 1 & 32 \\
180 & 00 & 00 & 180 & 2 & 15 & 2 & 15 \\
\hline
\end{tabular}


The center of the radial length of the aperture was used in the above calibration. This was considered satisfactory in this case for two reasons, first, because of the very high quality of the aperture edges a very definite setting edge is obtained making it unnecessary to determine the angle at several points to obtain a mean value, and, second, the method of filing the edges made it certain that they are nearly perfectly radial. Furthermore, the central part of the exposed square on the test plates (exposed by these apertures) are the portions used in the density measurements.

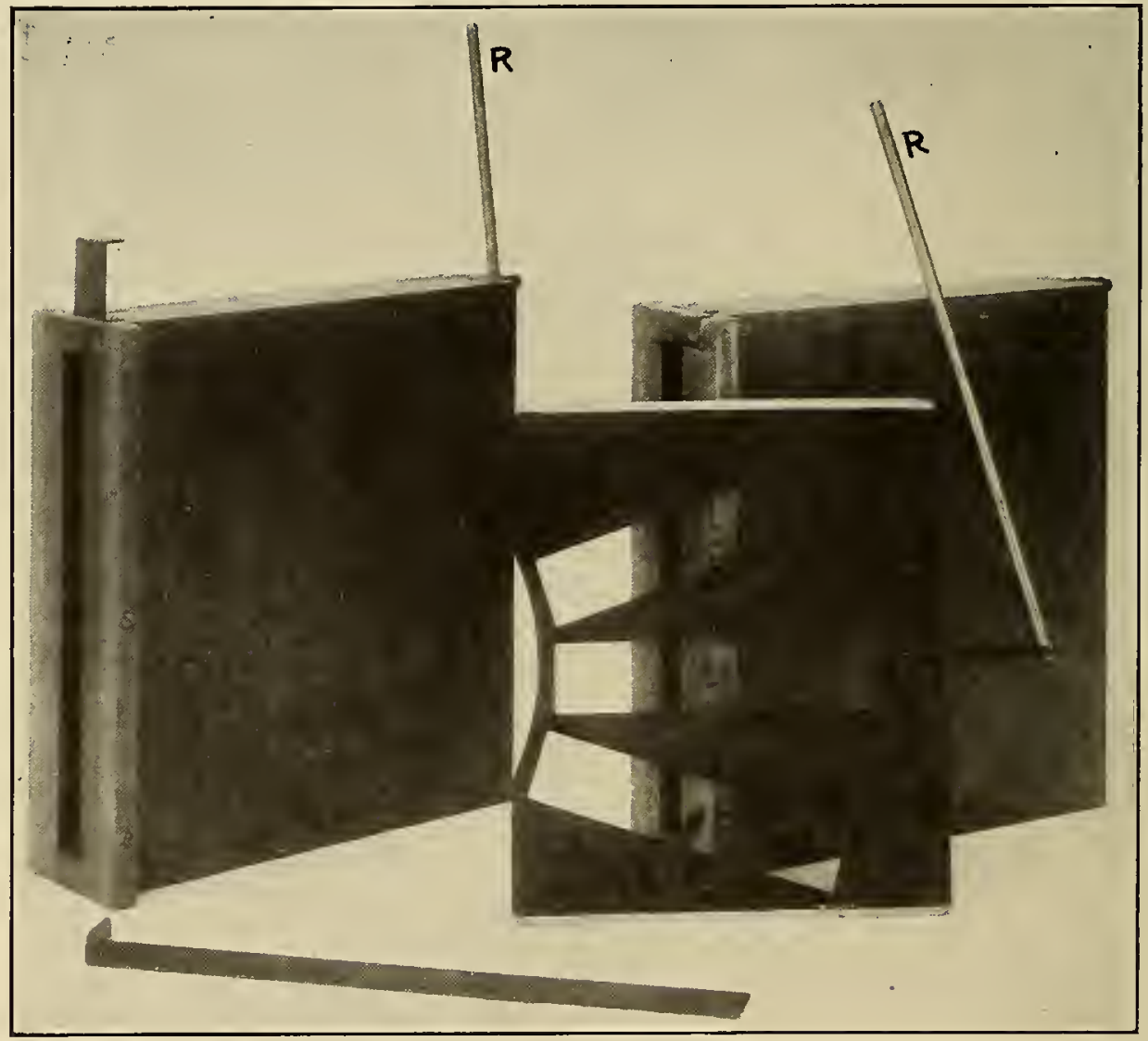

FIG. 12.-Showing two plate holders, one complete and the other with the plate slide removed

The probable accuracy of the above calibration varies somewhat with the size of the angle. It is considered to vary from less than \pm 10 seconds for the smaller ones to less than \pm 25 seconds for the largest.

\section{PLATE HOLDER, LAMP, AND SHUTTER DETAILS}

\section{PLATE HOLDER}

It is desirable to have the test plates as close as practicable to the sector wheel in order to get the true effective aperture and to eliminate partially illuminated shadows. The plate holder (fig. 12) 
is similar in design to those used in the old sensitometer. It holds three test plates $11 / 8$ by 5 inches, which are displayed radially from the center of the sector wheel when in position (see also fig. 3). The plates are in shallow pockets on a blackened metal plate which is slid on a track from the plate-holder box into position behind the sector wheel by means of the rod, $R$ (fig. 12).

It is the usual practice to expose one half of each test plate, the other half being used as a fog strip. In this sensitometer, a movable aperture plate containing three apertures for exposing either the upper or lower half of the test plate is in front of the sector wheel (see fig. 3). The control for this is shown at $A$, Figure 13.

\section{STANDARD LAMPS}

The standard of light intensity maintained by this bureau for its general emulsion testing is 1 candle meter visual, agreeing to this extent with the original standard of Hurter and Driffield. The color standard is an approximation of average yearly noon sunlight at Washington, color temperature $5,325^{\circ} \mathrm{K}$. The lamps used are the 6 to 8 volt Mazda $C$ type, operating on approximately 2.4 amperes. The lamps without filter give an average of 15 candlepower; the compensating filter (Corning daylight glass of proper thickness) transmitting 18.2 per cent, making an average intensity, as seen through the filter, of 2.73 candlepower. A Brooks deflection potentiometer is used to regulate the current accurately.

The light tunnel, which has been described, is adjustable in length from one-half to $2 \mathrm{~m}$. This adjustment is for the purpose of obtaining the desired intensity. A distance of less than $1 \mathrm{~m}$ is not used, except in special work where only a portion of one plate (the central one) is exposed.

One of the supporting rails or track for the light tunnel, lamp house, etc., is graduated in millimeters. This serves as a scale to indicate the distance from lamp to test plate.

\section{SHUTTER}

For long exposure; that is, several seconds or more, a simple handoperated flap shutter may be used with a nonintermittent exposure machine. As the apertures of the sector wheel are on one-half only a mark on the shaft outside the instrument can be used as a signal for opening or closing the shutter while the solid portion of the wheel covers the test plates. With higher rates of speed of the sector wheel the hand shutter must be replaced with a mechanical one.

The shutters designed for this instrument are, $A$, shutter for moderate speeds and, $B$, shutter for high speeds. 


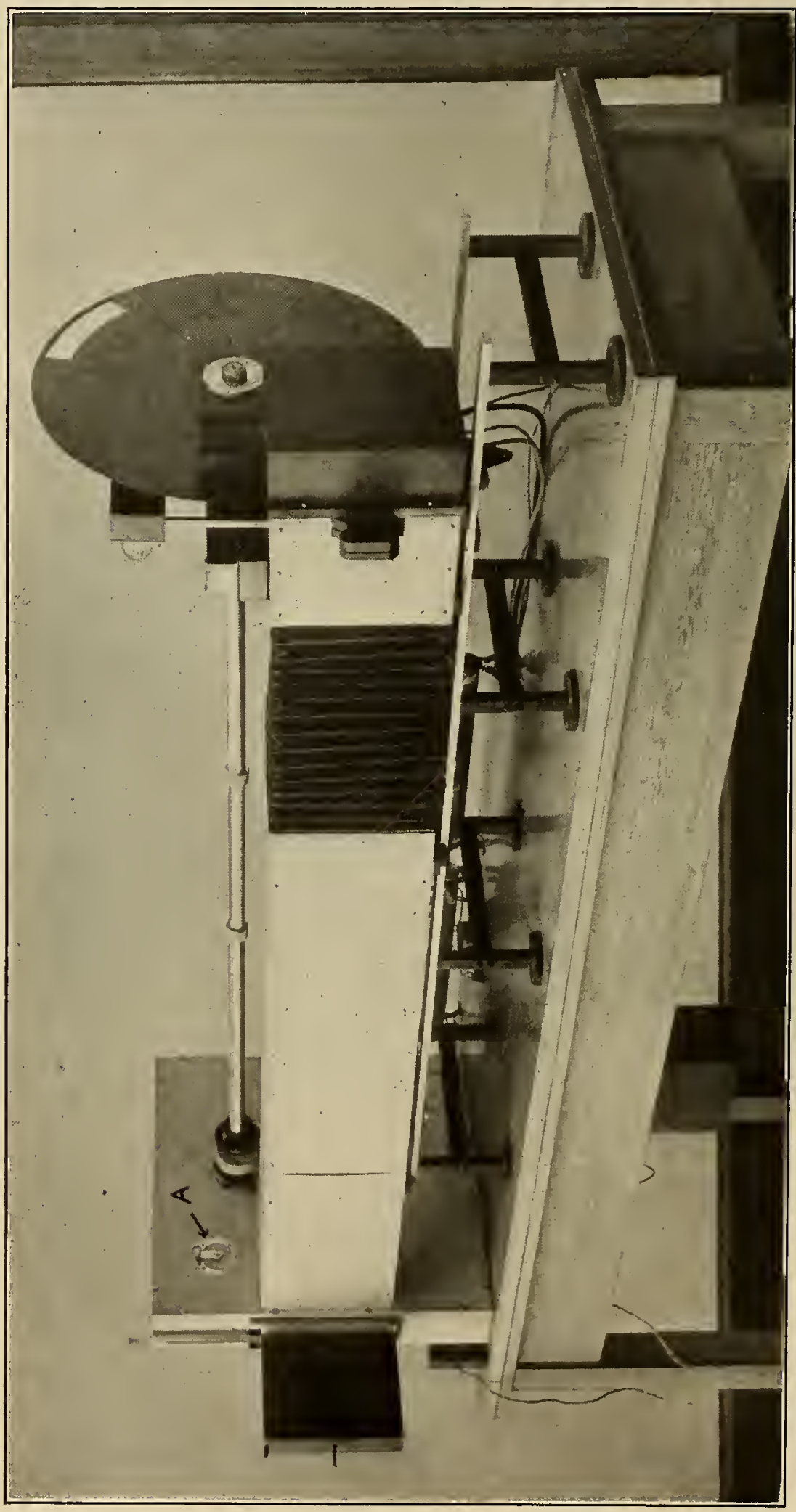

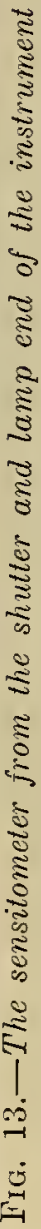


The shutter for both low and moderate speeds is an electrically operated one of spring-driven modified guillotine type. It is set by hand at a point below and outside of the lamp house (see fig. 14).

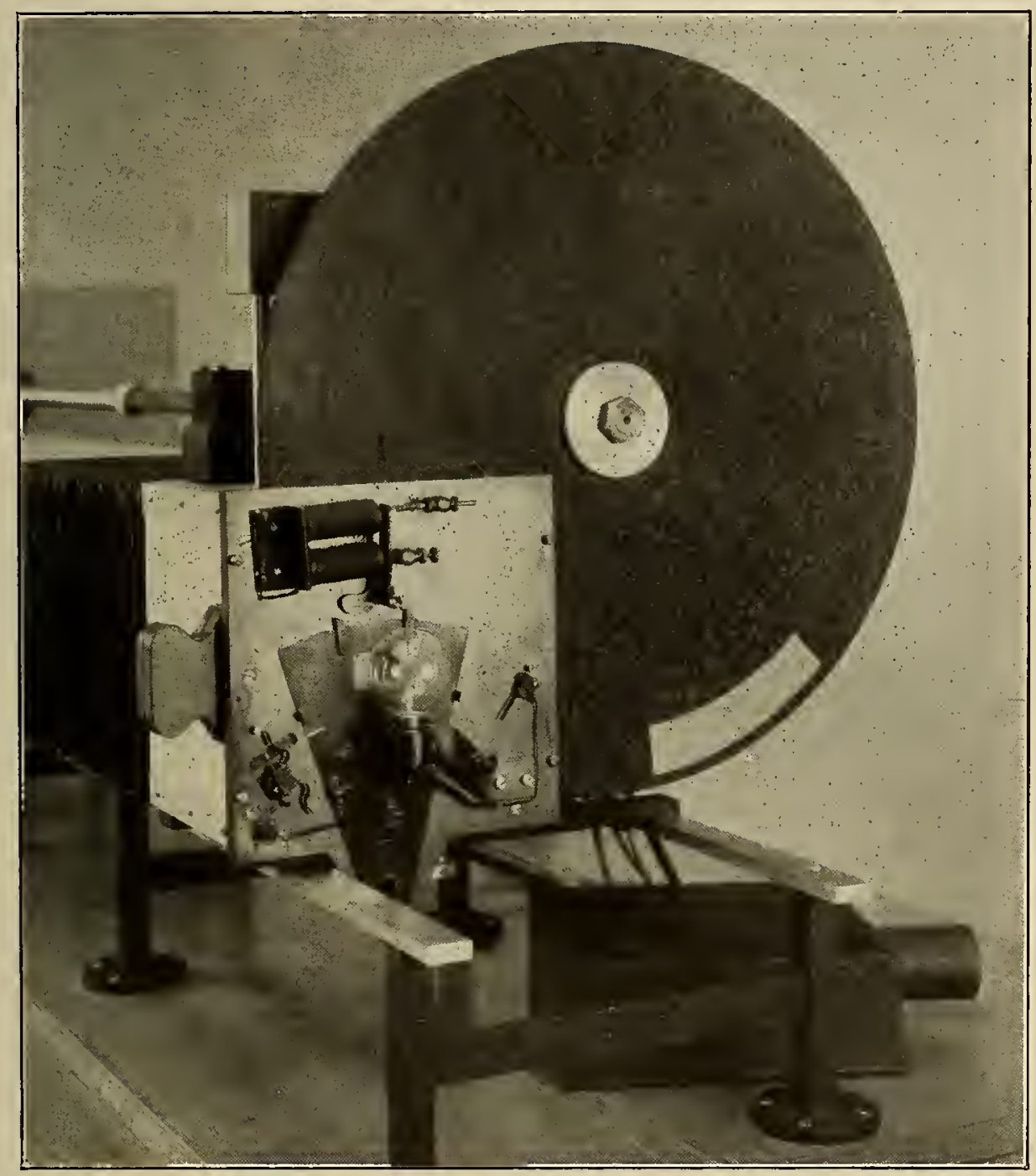

FIG. 14.-A close-up view of the shutter mechanism

Electromagnets, which operate an escapement when first energized, cause the shutter to open; the second impulse closes it. The time of opening and closing is determined by a commutator on the sectorwheel shaft seen in Figure 1. The exposure is started by pressing a button on a simple automatic timing switch, the commutator and brush on the sector-wheel shaft completing the circuit at the proper instant and opening the shutter. The next revolution of this commutator completes the circuit again, closing the shutter. In closing, the shutter blade completes another cireuit through a brush contact which opens the automatic switch (seen at $A S$, fig. 1). The electrical circuit is represented by the heary lines of Figure 15 . 
This shutter, though rugged and dependable, does not operate with sufficient speed to be reliable for exposures when the sector wheel is running at the higher speeds. These exposures are taken care of by the following device. Directly behind the aperture of the shutter is an auxiliary sector or shutter wheel on telescopic shafting connected by two gears to the sector-wheel shaft. This wheel is driven at one-eighth the speed of the sector wheel. At the maximum speed of the latter $(480 \mathrm{r} . \mathrm{p} . \mathrm{m}$.) the shutter wheel rotates at $60 \mathrm{r} . \mathrm{p} . \mathrm{m}$. It is provided with a single aperture which coincides with the shutter aperture once in eight revolutions of the sector wheel and only for the length of time necessary for the apertures of the sector wheel to move past the test plates. As shown at $C$, Figure 16, and on the wiring diagram, Figure 15, a second commutator on the auxiliary

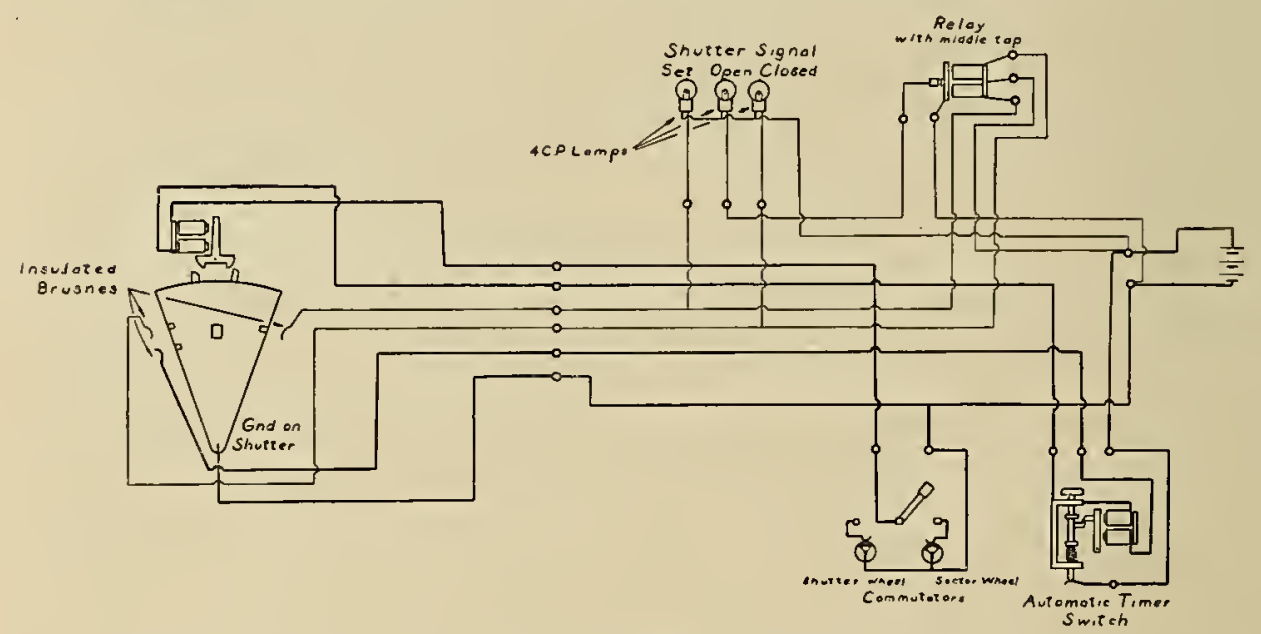

FIG. 15.-Wiring diagram of the shutter and shutter signal circuits

shaft controls the opening and closing of the shutter, replacing the one on the sector-wheel shaft for the high-speed exposures. This shutter mechanism could easily be used to make single exposures at $960 \mathrm{r} . \mathrm{p} . \mathrm{m}$. of the sector wheel, and by the addition of other shutter wheels properly geared together the minimum exposure interral is limited solely by the speed at which the sector wheel may be rotated.

\section{SHUTTER SIGNAL}

The guillotine shutter being inclosed in the lamp house, a simple signal arrangement is provided to show when it is in each of its three successive positions, namely, set, open, and closed. A miniature electric sign to indicate these positions is operated through two contacts on the shutter, one of which completes a circuit when it is in the set position, the other closes another circuit when the shutter is closed. These two circuits are carried independently through the magnets of a relay, so that if either circuit is completed the armature 


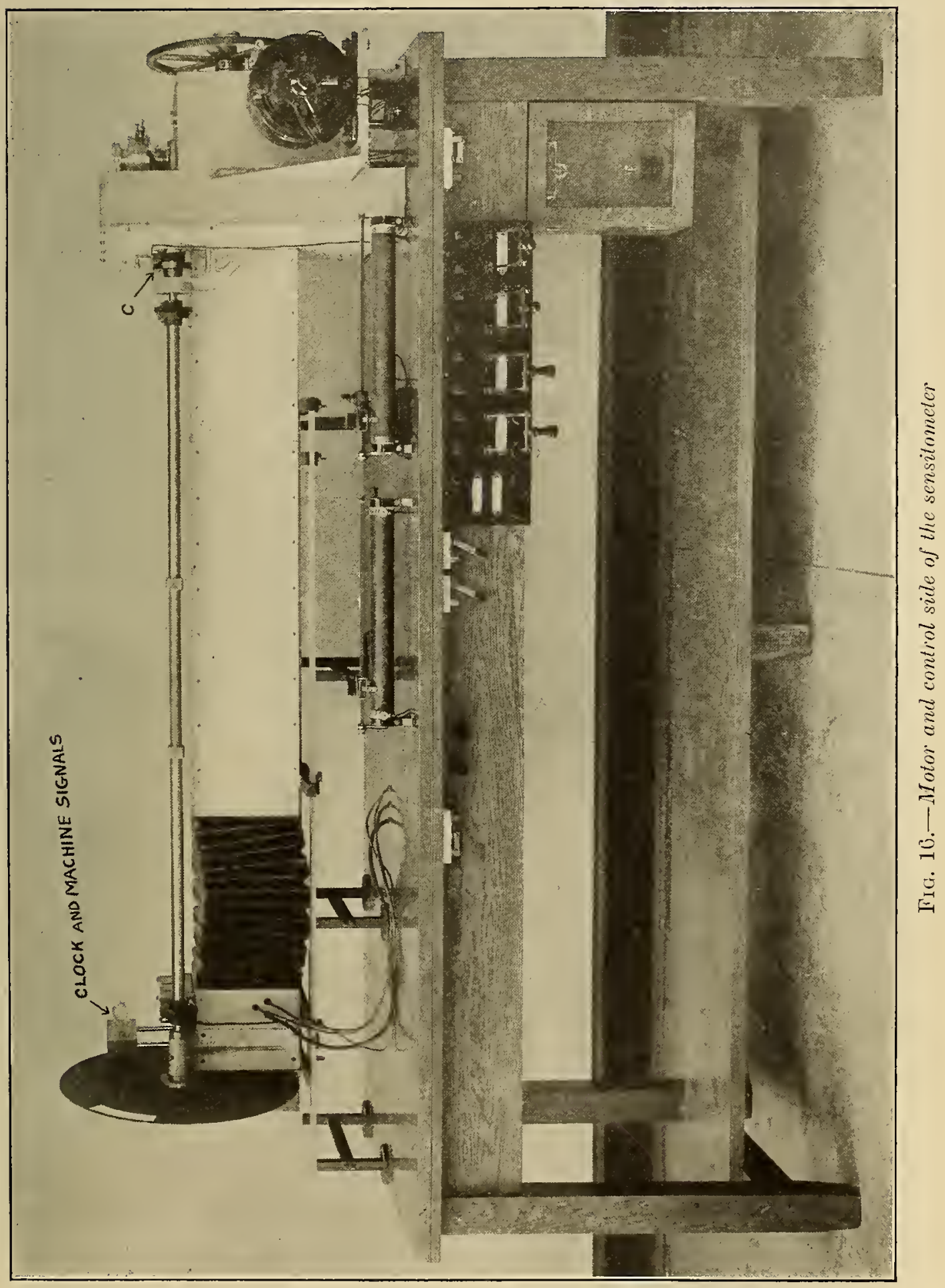


is actuated, opening a third circuit, that of the open position signal. This third circuit is closed if neither the open nor closed signal circuits are completed. In this manner the three position signals are operated by two contacts on the shutter. This is best seen from the wiring diagram (fig. 15), in which the light lines are the shutter signal circuits.

\section{SPEED REGULATION}

\section{CONSTANT-SPEED DRIVING MOTOR}

One of the chief difficulties in the planning of a noninternittent sensitometer of this type is the selection of a suitable method for driving the sector wheel at a uniform and accurately known speed. In the case of this apparatus a wide range of loads must be taken care of by the motor. Roughly, the load variation is proportional to the sector wheel speeds, which are from 1 to 8,192 in power-of-two steps. Of course, a large part of these are in the light-load class, but even when this is taken into account a large difference in power required to drive the sector wheel at the different speeds must be considered. If an alternating-current supply of constant frequency were available, a synchronous motor could be used with excellent results. Another device which is often used to cbtain constant speed is the direct-current series motor controlled by a governor which regulates the current supply to the motor. This is also satisfactory if the load is nearly constant and the line fluctuations are small. It is quite evident that the latter arrangement would require an additional regulation or adjustment of the motor current to compensate for a change in load.

The use of a shunt motor seems desirable as a source of power for constant speed because under constant voltage it is inherently a constant-speed derice, even under varying load. The fact that the electrical characteristics of the armature circuit are such as to allow quite rapid response of the armature current to changes of voltage makes the motor respond quickly to an increase in voltage; and, on the other hand, the dynamic braking effect available in this motor aids greatly in obtaining quick response to a decrease in voltage. From a theoretical point of view it is desirable to have the control current regulated at as rapid a rate as possible to obtain the most uniform rate of speed of the motor and also that the motor shall be rapid in response. Thus the shunt motor seems peculiarly adapted for speed control if the corrective device operates in the armature circuit.

The characteristic of this motor is quite conclusively demonstrated by the use of the so-called potentiometer control circuit which was used on the old sensitometer (see fig. 15, Sci. Paper No. 439) and is reproduced here as Figure 17. If the $40-\mathrm{olm}$ resistance which is 
across the line is uniform throughout its length, then the voltage applied to the armature is in direct proportion of the line voltage to the relative position of the slider. When the slider is moved to the left end of the resistance, full-line voltage is on the armature and the motor runs at full speed. Now, if the slider is quickly moved to the right the voltage as applied to the armature is suddenly reduced and the motor almost instantly reduces its speed to a value corresponding to the new lower value of armature voltage.

The above considerations led the writer to attempt to apply the centrifugal governor to the shunt-wound motor. The plan devised employs as a basis the circuit just described. A one-eighth-horsepower motor, rated speed of 1,750 r. p. m., is run at the slightly reduced speed of 1,500 r. p. m. The governor is mounted on the worm

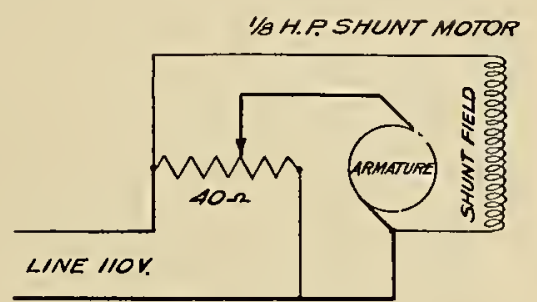

Fig. 17.-Wiring diagram showing a method of regulating the armature voltage to control the speed and retain the characteristics of the shunt motor shaft of the sensitometer, which is directly connected to the motor. This is shown at $G$, Figures 1 and 3 . The wiring diagram (fig. 18) shows the motor and governor circuits. With this arrangement the motor field receives full-line voltage, the armature a slightly reduced voltage, which is varied between two values determined by the governor adjustment, and the speed at which it is desired to run the motor. One of the values of armature voltage is above that corre-

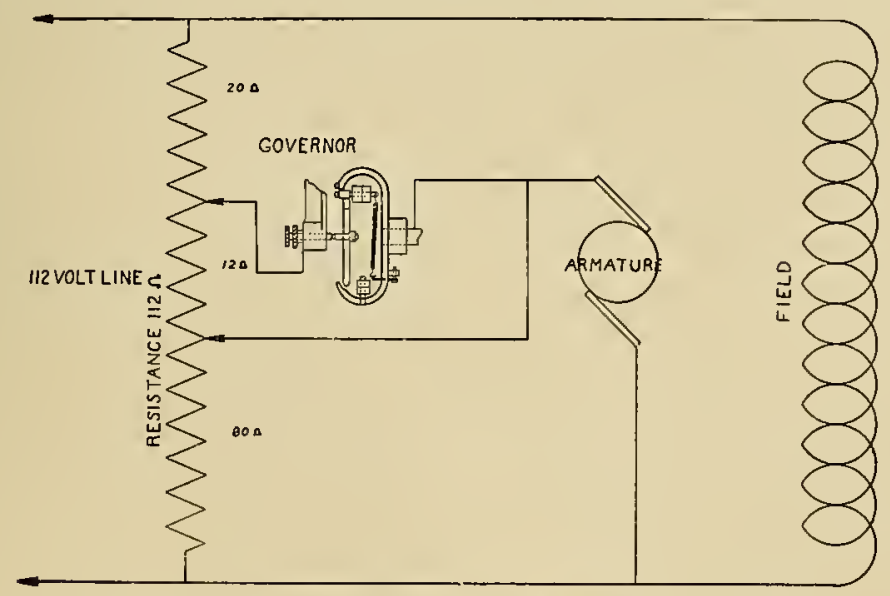

FL.G. 18. - Shunt motor and governor of circuits

sponding to the desired speed, and the other below it. The governor opens its circuit when above its adjusted value of speed and closes the circuit if the speed is below it. Its function is simply to shortcircuit a small section of the potentiometer rheostat. The effect of this may be explained as follows: Referring to Figure 18 let us 
assume, for convenience, that the motor draws no current and that the line voltage is 112 volts, the total resistance of the potentiometer is $112 \mathrm{ohms}$, the slider at the point $B$ is $80 \mathrm{ohms}$ from $A$, the slider, $C, 12 \mathrm{ohms}$ from $B$, and from $B$ to $D$ is $20 \mathrm{ohms}$. Now if the governor circuit is open the armature is supplied with 80 volts. When the governor circuit is closed, the section between $B$ and $C$ is shortcircuited and the potentiometer now has a total resistance of $100 \mathrm{ohms}$; consequently the armature voltage is now $80 / 100$ of the line voltage, or 89 volts.

In practice the voltage of the governor circuit is about 13 volts, with a current of about 0.2 to 0.4 of an ampere; the rate of interruptions of the governor is high and quite constant at 49 per second. For each change of load the position of the slider on the resistance, which controls the armature and governor circuits, require an adjustment. With this method a good constant speed is obtained if the line voltage fluctuations are small. A refinement, however, has been added which greatly increases the precision in regulation. This is described under $\mathrm{V}, 3$.

\section{COMPARISON OF MACHINE SPEED WITH CLOCK}

The purpose of the sensitometer is to expose the photographic emulsion to an accurately known intensity of light for a precise interval of time. The apertures in the sector wheel give definite relative exposures, but to know the exact value of the time of exposure it is necessary to know with precision the velocity of the sector wheel. With a sensitometer of this type some form of tachometer could be used for this purpose, but not with the precision that can be had by direct comparison with a clock. This has been provided as follows: On the upper end of shaft $D$, which, as previously explained, revolves at 15 r. p. m., is mounted a commutator. This commutator has four equally spaced segments which make electrical contacts through a brush at the rate of one a second. The current through this commutator is used to light a lamp for an instant at each contact. The penduium of a seconds-sweep clock, equipped with a mercury contact, is utilized to flash a similar signal in the same manner.

These two signals are brought into synchronism by adjusting the position of the commutator brush, at $S$ (fig. 3). This method is fully as sensitive as signals from telegraph sounders, with the decided advantage that not only the difference, but the direction as well (machine fast or slow) can be determined at a glance. The effect of direction or motion obtained is similar to that in the electric sign. 


\section{AN AUTOMATIC SYNCHRONIZER}

The flashing lamp-signal arrangement is very satisfactory for comparing the machine time with clock time. The governed motor was found to drive the machine in nearly perfect synchronism with the clock for periods varying from two to eight minutes. While a motor fitted with a governor may be depended upon to maintain a good constant speed it will not keep good clock time over long intervals, because its errors are irregular and may be cumulative. A method for improvement was sought and a solution found as follows: There are, as stated, two separate electric signals at one-second intervals, one from the machine and the other from the clock. These signals when synchronized arrive together for a while, but eventually a difference of the time of arrival is observed. If the motor is running too fast, the machine signal will come first, if too slow, the clock signal arrives first. This difference, and the direction of the difference is made use of by employing what we shall call a "differential relay," which is a double relay with a common (single) armature free to move to one side or the other, depending upon which magnet is energized. These two signal circuits are carried through this relay one on each side. If they arrive at the same instant, they oppose each other and the armature of the differential relay is not moved. Should one of these arrive before the other, the armature is moved to that side. Of the two electromagnets composing each side of this relay, only one is used for the signal circuits, the companion magnets are units in two corrector circuits which are completed by the armature contacts when the armature is moved from the neutral position to one side. This causes the armature to be held over until the circuit is broken elsewhere. By means of a commutator this circuit remains unbroken for two-fifths of a second. During this interval, through other relays in the circuit, a small correction is applied to the motor current to increase or decrease the motor speed to compensate for its failure to keep clock time, thus bringing the machine back into synchronism with the clock. This correction is automatically applied once a second if necessary.

Figure 19 gives the wiring diagram. From left to right are the lamp-signal circuits, differential-relay circuits, corrector circuits, and, last, the governor and motor circuits. The upper half of the first four circuits is controlled by the machine and the lower half by the clock. With the machine and clock in step, relay 1 short-circuits $R-1$ of the governor circuit. Should the machine be ahead, relay 1 opens the circuit on $R-1$ and decreases the current through the governor circuit by the added resistance of $R-1$. When behind, relay 2 short-circuits $R-2$ thereby increasing the current in the governor circuit. The magnitude of this current determines the strength of the impulse given to the motor by the governor. 
A defect in the method of applying the correction for two-fifths of a second by means of a commutator should be noted. This commutator being part of the machine, the presence of a difference of, say, one-fifth of a second between the signals leaves it but one-fifth of a second to apply the correction to the motor which may be insufficient if the correction provided is small, as should be the case. Furthermore, if the difference should exceed two-fifths of a second, the correction is then applied in the wrong direction, the commutator being in position to apply the correction through the other circuit. In practice, however, an error of this magnitude only occurs when the corrector circuits are cut in before the motor has become warm

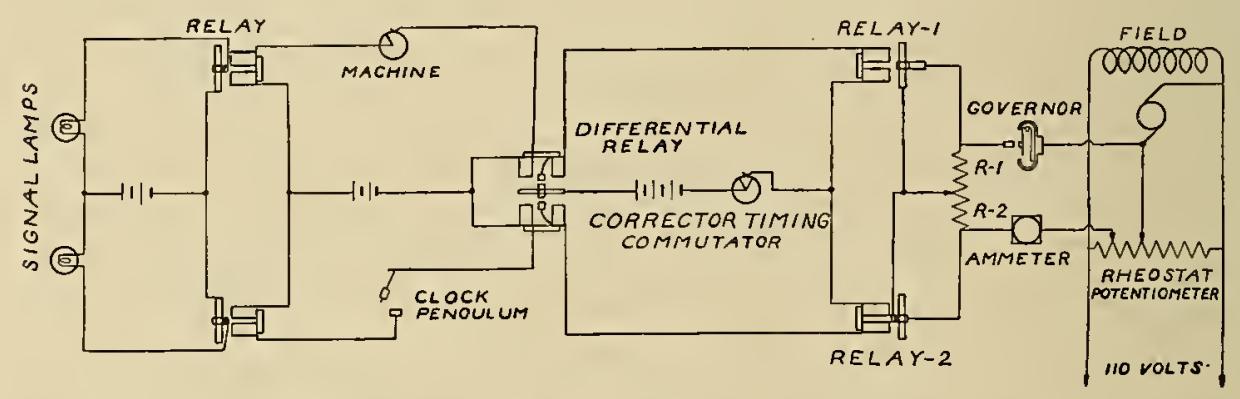

FIG. 19. - Complete diagram of machine, clock, motor, and governor circuits

and in a stable condition. The use of a delayed action break-circuit switch, instead of the commutator, would avoid this trouble.

The differential relay was made from two ordinary relays by sawing off half of the bridge and putting the two groups of magnets in a position to act on one armature. In this form it is entirely too sensitive to be of use for the purpose. The sensitivity was decreased by fitting to the armature a rod and weight similar to a pendulum, and a vane was secured to the lower end of this which dips in oil for the purpose of damping. Figure 20 shows the completed instrument. Its position on the sensitometer may be seen in Figure 16 .

The machine as shown in Figure 16 is complete, the relays and other instruments which are not visible being mounted under the table. 


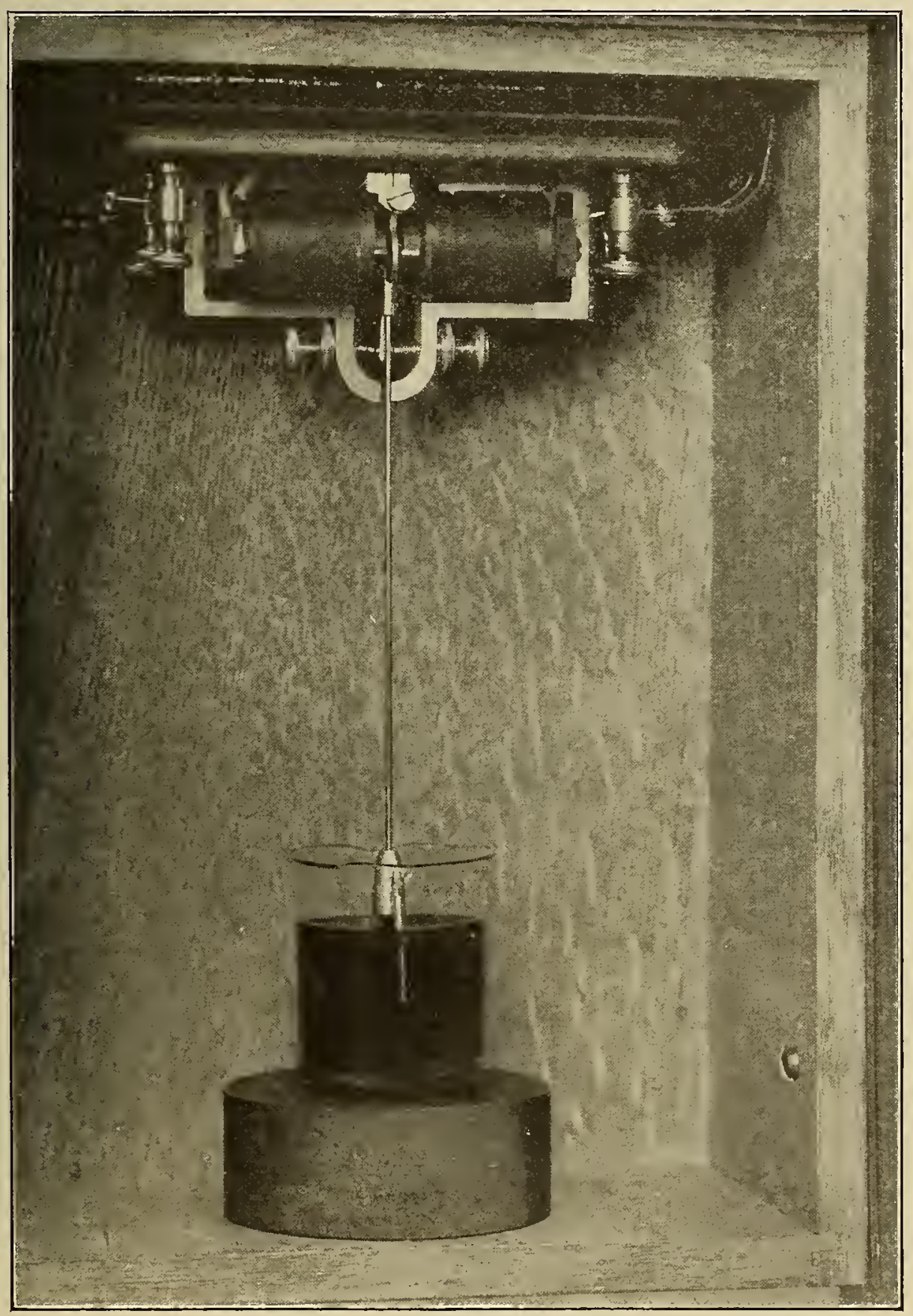

FIG. 20.-The differential relay 


\section{SUMMARY}

This paper is a description of a nonintermittent exposure machine constructed for use in photographic research.

A short résumé is given of similar apparatus followed by a somewhat detailed description of the principal parts and their functions.

Several modifications of sector-wheel design are discussed and the procedure given for calibrating the angular apertures together with the precision attained.

A new circuit is made use of for adapting the shunt motor to the centrifugal governor for the purpose of driving the apparatus. Another feature is the method employed to correct incidental irregularities in the motor speed by synchronizing its rate with clock signals.

In conclusion, the writer desires to express his indebtedness to Frederick Knoop, of the instrument shop, for the skill and precision with which the plans were executed, and to Paul T. Howard for assistance in assembling the apparatus and in the calibration of the sector wheels.

\section{BIBLIOGRAPHY}

1. Davis, R., and Walters, F. M., Sensitometry of Photographic Emulsions, Bureau of Standards Sci. Paper No. 439.

2. Abney, W de W., Photo. Jour. 18, p. 56; 1893; also Schwarzschild, K, Astro. Phys. Jour., 11, p. 92.

3. (Most recent work), Kron, E. Potsdam Astrophys. Obs. Nr. 67, 1913; Helmick, P. S., J. O. S. A., 5, p. 336; 1921; Jones and Huse, J. O. S. A. and R. S. I., p. 1079; December, 1923.

4. Jones, L. A., Photo. Jour., 1920, p. 86.

5. Jones, L. A., J. O. S. A. and R. S. I., April, 1923, p. 149.

6. Jones, L. A., Photo. Jour., 1920, p. 80.

7. Higson, G. I., Photo. Jour., 1920, p. 235.

8. Hardy, A. C., J. O. S. A. and R. S. I., Fcbruary, 1925, p. 149.

9. Renwick, F. F., Photo. Jour., March, 1920, p. 99.

10. Drifficld, V. C., Photo Miniature, 56, November, 1903.

11. Eder, J. M., Handbuch der Photographie, 1912, Heft, 3, p. 168.

Washington, May 1, 1925. 